\title{
Experimental and Theoretical Study of the Effect of Adding Ion Exchange Bed to RO Desalination System
}

\author{
A. E. Kabeel ${ }^{1}$, A. Khali1 ${ }^{1}$, Y.A. F. EL-Samadony ${ }^{2}$, and Maisa A. Sharaf ${ }^{3, *}$ \\ ${ }^{1}$ Mechanical Eng. Department, Faculty of Engineering, Tanta University, Tanta, Egypt \\ ${ }^{2}$ Mechanical Eng. Department, Faculty of Engineering, Beirut Arab University, Beirut, Lebanon \\ ${ }^{3}$ Mechanical Eng. Department, Faculty of Engineering, Kafrelsheikh University, KafrElsheikh, Egypt \\ * Corresponding author, E-mail address: mech.enge@yahoo.com
}

\begin{abstract}
In the present work, a novel hybrid reverse osmosis (RO) system with ion exchange (IX) bed is designed and studied experimentally and theoretically. This is done by adding a new IX bed before conventional RO system. Natural zeolite is chosen as a cheap adsorbent for IX process. The present work investigates IX process in continuous water flow bed. The effect of natural zeolite mass, water flow rate, bed diameter and natural zeolite grain size on the performance of IX bed is studied. Moreover, water recovery, permeate water and membrane flux of RO system are studied and compared with the conventional RO system. The results showed that the proposed system water recovery, permeate water and membrane flux is higher than that for conventional RO system by $9 \%$ to $27.1 \%, 8.5 \%$ to $29 \%$ and $30 \%$ respectively at different inlet water concentrations for zeolite bed with $250 \mathrm{~g}$ weight. Finally, a good agreement between theoretical and experimental results is performed.
\end{abstract}

Keywords: Desalination, Reverse osmosis, Ion exchange, Membrane recovery

\section{INTRODUCTION}

Salinity of water is a significant problem in many parts of the world. Desalination system, as a method of producing drinking water; is predicted to spread and become more applicable in the world. The most important method that used in desalination process is reverse osmosis (RO). This desalination method, however; suffers from a number of disadvantages as it requires high pressures in order to overcome the natural osmotic pressure of saline Water. Also, precipitation of salts from the input saline solution can form deposits on RO membranes causing a reduction in membrane efficiency and high expenses of energy.

To enhance the water permeability of an RO system, the work in [1] investigated experimentally the effect of using a highly porous microstructured support membrane. They found that their proposed system water permeability was surpassing commercial RO membranes and thin-film nanocomposite membranes. In [2], Atab et al. studied numerically the performance of a new hybrid reverse osmosis with adsorption desalination system. This hybrid system was succeeded to produce large amount of water for irrigation and high quality water for drinking. Moreover, their proposed system can produce water air-conditioning. Therefore, this system may be considered as the optimum solution for countryside areas. In [3], Parlar et al. compared between conventional reverse osmosis (RO) system with reverse osmosis (RO) integrated nanofiltration. They found that the permeate quality and the amount of drinking output water were significantly better if nanofiltration was added to the system.

Ion exchange (IX) may be defined as the process at which ions exchanged between two electrolytes or between a complex and an electrolyte solution. Ion exchange (IX) resins are coated with substituting hydrogen ions and hydroxide ions for two main phases of the ion exchange process respectively. Consequently, IX resins are used in water treatment application. In the cation phase the hydrogen ions will be exchanged with sodium ions from sodium chloride salt in the water being processed. During the anion phase the chloride ions is exchanged with hydroxide ions [4]. Zeolites are natural ion exchange (IX) material with porous structures and capable of exchanging cations [5]. Zeolites have a negative charge, which originates from the replacement of Silicon with Aluminum and balanced with cations such as potassium, sodium, magnesium and calcium [6]. Zeolites material has high ion exchange (IX) ability for cations and for its molecular sieve properties, it was used in water purification and removal of heavy metals processes [6] Moreover, due to its negative charge, natural zeolites have a small attraction for anions and low adsorption for organics in aqueous salt solution [7]. There are different zeolite types with different cations preferences. The most used and available types are Clinoptilolite and chabazite zeolites, which have a partiality for larger cations. Clinoptilolite selects cation in the following order: $\mathrm{Cs}>\mathrm{Rb}>\mathrm{K}>\mathrm{NH} 4>$ $\mathrm{Ba}>\mathrm{Sr}>\mathrm{Na}>\mathrm{Ca}>\mathrm{Fe}>\mathrm{Al}>\mathrm{Mg}>\mathrm{Li}$ [8].

Natural zeolites were used to decrease sodium ions from produced water by replacing them with calcium, thus reducing sodium concentration. The work in [9] reported that natural zeolites could become a cost efficient technology for the treatment of high sodium concentration of coal seam gas (CSG) co-produced water. Moreover, natural zeolites were considered as low cost material with abundant availability and have high sorptibility for inorganic and organic ions. In addition, Natural zeolite is easy of activation and regeneration and nontoxic material $[10,11]$. In [12], the sorption ability of zeolite by the reduction of salinity and efficiency of that reduction were studied. The highest value of reduced salinity and efficiency were $3200 \mathrm{ppm}$ and $9.14 \%$, respectively with $7.5 \mathrm{~g}$ of sorbent material. They found also that the desalination process effectiveness can be enhanced 
by increasing the zeolite weight as in [13] which proved that untreated natural zeolite had a capacity of $16.16 \mathrm{mEq} / 100 \mathrm{~g}$ to adsorb sodium ions. In [14], they examined the elimination of sodium ions from waters with utilization of calcium rich natural zeolites. They found that the maximum adsorption capacities for BR-Zeolite and ST-Zeolite were 12.3 and $9.6 \mathrm{mg} / \mathrm{g}$, respectively, which equal approximately $38 \%$ and $39 \%$ of their measured cation exchange capacity values.

In [15], the effect of Rhyolitic tuff and clinoptilolite on sodium adsorption ratio (SAR) and the total dissolved solids (TDS) reduction in a reverse osmosis (RO) system concentrate were studied. They found that the two types of zeolites decrease the SAR and TDS of waste water by neglecting the residence time, however clinoptilolite decreases the water salinity. The ion exchange (IX) process comprising the steps of exposing water containing sodium chloride to an ion exchange material in divalent form, where monovalent sodium ions are exchanged for divalent or polyvalent ions, thereby producing a solution with an osmotic pressure lower than the osmotic pressure of water containing sodium chloride, and using the solution as feed water of a semi-permeable membrane for separating ions from the solution and producing desalinated Water [16, 17]. In [18], the effect of using zeolite on desalination of saline sludges was studied. They kept the water in the IX (zeolite) column for $20 \mathrm{~min}$ and then drained. They found that the efficiency of sodium salt removal was $72.25 \%$ and increased to $92.96 \%$ when using two ion exchange columns.

It could be noted from the previous review or up to the author's knowledge, zeolite IX material studied in contact with water tank or column but never studied in IX bed before reverse osmosis (RO) system. In the present work, a novel hybrid IX and RO system is designed and studied. This is done by adding a new IX bed before RO system. Therefore, IX processes will be examined in a continuous water flow system. Natural zeolite is chosen as a cheap (100\$/ton) adsorbent for IX process. The main aim of the IX process is to enhance the RO performance by reducing feed water electrical conductivity and hence decreasing the cost of the produced potable water.

\section{EXPERIMENTAL WORK}

\section{A. Materials}

There are many types of natural zeolites. We used Clinoptilolite because it is the most abundant and low cost type. Table 1 shows the chemical composition of major elements for used natural zeolites (Clinoptilolite), which was reported from the central metallurgical research institute (CMDRI) for A\&O Company. Synthetic feed water was made by addition of appropriate amount of Sodium Chloride salt to filterated water from RO system.

TABLE I

CHEMICAL COMPOSITIONS FOR MAJOR ELEMENTS OF USED NATURAL ZEOLITE

\begin{tabular}{|l|l|l|l|l|l|l|l|}
\hline $\mathrm{SiO}_{2}$ & $\mathrm{Al}_{2} \mathrm{O}_{3}$ & $\mathrm{Fe}_{2} \mathrm{O}_{3}$ & $\mathrm{CaO}$ & $\mathrm{MgO}$ & $\mathrm{Na}_{2} \mathrm{O}$ & $\mathrm{K}_{2} \mathrm{O}$ & $\mathrm{TiO}_{2}$ \\
\hline 62.22 & 11.096 & 4.033 & 3.583 & 0.599 & 0.78 & 3.266 & 0.339 \\
\hline
\end{tabular}

\section{B. Experimental apparatus}

The experiment is divided into two stages. The first stage is the IX process by natural zeolite bed, and second stage is RO process, as shown in Fig. 1. The First stage consists of a tank for the feed water, feed water pump with speed controller, IX bed (zeolites bed) and IX outlet tank. IX bed has a cylindrical shape with $7 \mathrm{~cm}$ diameter and $25 \mathrm{~cm}$ height. As IX process needs about 20 min contact time or more (Ghaly \& Verma, 2008) therefore the used feed water pump runs with a very small flow rate of $30 \mathrm{ml} / \mathrm{min}$. The IX process performance was evaluated by means of the solution $\mathrm{pH}$ and electrical conductivity measurements.

The experiment is divided into two stages. The first stage is the IX process by natural zeolite bed, and second stage is RO process, as shown in Fig. 1. The First stage consists of a tank for the feed water, feed water pump with speed controller, IX bed (zeolites bed) and IX outlet tank. IX bed has a cylindrical shape with $7 \mathrm{~cm}$ diameter and $25 \mathrm{~cm}$ height. As IX process needs about 20 min contact time or more [18]. Therefore, the used feed water pump runs with a very small flow rate of $30 \mathrm{ml} / \mathrm{min}$. The IX process performance was evaluated by means of the solution $\mathrm{pH}$ and electrical conductivity measurements.

In the reverse osmosis (RO) process, this process uses the produced water from the IX process to the membrane. This stage consists of a diaphragm pump (Water world CDP-9000, maximum flow rate of $1.6 \mathrm{Lpm}$, maximum pressure of 80 psig, and motor 24VDC/1.2A), adjustable DC power supply, pressure regulator in the produced line, and finally a spiral wound RO membrane FilmTecTM TW30-1812-100. The system was also completed with pressure indicator $(0-140$ psig).

Electrical conductivity is measured by electrical conductivity probe (KDS-1038) from ScienceCube. $\mathrm{pH}$ is measured by inoLab pH 720 from WTW GmbH.

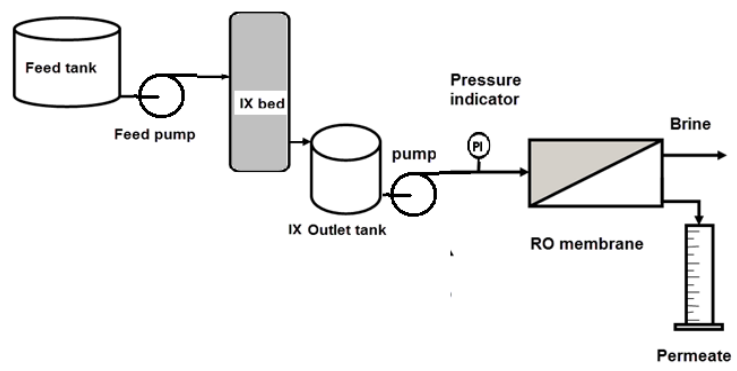

Figure 1. The proposed hybrid system set up

\section{THEORETICAL ANALYSIS}

\section{A. Zeolite IX bed process}

A theoretical simulation of the IX process was done using MATLAB program code. Advection diffusion equation is used to describe mass transport in column bed filled with porous media where advection causes translation of the solute with the flow velocity and dispersion causes solute spreading. For one dimensional flow in the vertical direction, the advection diffusion equation (ADE) formed in [19] is used: 
$\frac{\partial C}{\partial t}=D \frac{\partial^{2} C}{\partial Z^{2}}-V \frac{\partial C}{\partial Z}$

where $\mathrm{C}$ is the solute concentration (ppm), $\mathrm{t}$ is time (s), $\mathrm{Z}$ is the vertical coordinate $(\mathrm{m}), \mathrm{D}$ is the diffusion coefficient $(\mathrm{m} 2 / \mathrm{s})$ and $\mathrm{V}$ is the advection velocity of the flow $(\mathrm{m} / \mathrm{s})$.

Forward difference scheme is used for the first order derivative of function and central difference scheme is used for the second one. The final form of numerical solution by finite difference method (FDM) in implicit condition is given as follows:

Forward difference scheme:

$$
\frac{\partial C}{\partial Z}=\frac{C_{i+1}-C_{i}}{\Delta Z}
$$

Central difference scheme:

$$
\frac{\partial^{2} C}{\partial Z^{2}}=\frac{C_{i-1}-2 C_{i}+C_{i+1}}{\Delta Z^{2}}
$$

From equations (1), (2), and (3), the final form of ADE in [20] is as follow:

$-D \frac{\Delta t}{\Delta Z^{2}} C_{i-1}^{t+1}+C_{i}^{t+1}\left(1-V \frac{\Delta t}{\Delta Z}+2 D \frac{\Delta t}{\Delta Z^{2}}\right)+C_{i+1}^{t+1}\left(V \frac{\Delta t}{\Delta Z}-D \frac{\Delta t}{\Delta Z^{2}}\right)=C_{i}^{t}$

where the diffusion coefficient $\mathrm{D}(\mathrm{m} 2 / \mathrm{s})$ was estimated in [21].

\section{Reverse osmosis performance calculations}

There are many calculations methods that are used to judge the performance of an RO system and also for design considerations. In the present work, membrane recovery $\%$, and salt rejection $\%$, are used to judge the performance of an RO system after adding the new IX bed to determine its effect on RO system.

Membrane percent recovery, $\mathrm{Re} \%$, was defined as the percentage of permeate (being recovered) to feed water flow rate and is calculated as follows:

$$
\operatorname{Re} \%=\frac{Q_{p}}{Q_{f}} X 100
$$

where $Q_{P}$ and $Q_{f}$ are the flow rate of permeate and feed water in $\left(\mathrm{m}^{3} / \mathrm{h}\right)$, respectively.

$$
J=\frac{V}{A t}
$$

where $\mathrm{J}$ is the membrane flux $\left(\mathrm{L} / \mathrm{m}^{2} . \mathrm{h}\right), \mathrm{V}$ is the permeate volume $(\mathrm{L}), \mathrm{A}$ is the membrane area $\left(\mathrm{m}^{2}\right)$ and $\mathrm{t}$ is the time (h).

The salt rejection, (SR \%), is the measure of the effectiveness the RO membranes in removing contaminants. The salt rejection, (SR \%) is calculated by the salt concentration difference in the feed and permeate solution:

$$
S R \%=\left(1-\frac{C_{p}}{C_{f}}\right) \times 100
$$

where $C_{p}$ and $C_{f}$ are the concentration of salt in permeate and feed solutions $(\mathrm{mg} / \mathrm{L})$, respectively.

\section{RESULTS AND DISCUSSION}

The results include the performance of IX process when it works in continuous water flow bed and will be presented experimentally and theoretically. In addition, the performance of hybrid RO system when IX bed is added before RO will be presented.

A. Performance of continuous water flow $I X$ processes Experimental results

Figs. 1 to 4 illustrate the variation of the electrical conductivity of IX produced water (at zeolite bed outlet) with time for different amount zeolite mass in the bed and inlet water with TDS of 1060, 1660 and 2020 ppm, respectively. The water solution electrical conductivity is measured at zeolite bed inlet (inlet condition at $\mathrm{t}=0$ ) and then at the bed outlet. The water flow spends about $30 \mathrm{~min}$ to arrived to the zeolite bed outlet, therefore the first measuring point of the produced water (at the bed outlet) is measured after about 30 min or more, as shown in Figs. 2 to 4 . It could be noted that the produced water solution electrical conductivity firstly sharply decreases by about $0.90 \%$ to $19.2 \%$ and then increases with time. This is because natural zeolite uptake the sodium ions and this lead to electrical conductivity decreasing. Also, it is noted that, for the studied range of water pump flow rate, zeolite mass and TDS, the lowest achievement of the produced water solution electrical conductivity is occurred at 250 gm zeolite mass, which equivalent to 8.33 grams of natural zeolite per $\mathrm{ml} / \mathrm{min}$ of water flow rate $(\varnothing)$.

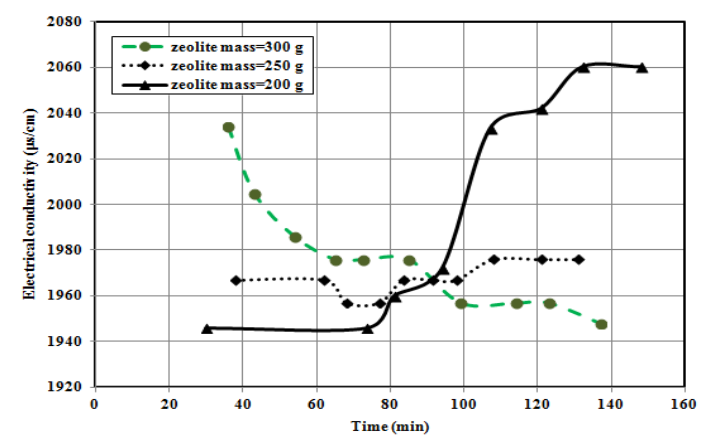

Figure 2. Variation of the produced water solution electrical conductivity with time for different amount zeolite mass in the zeolite bed when solution $\mathrm{TDS}=1060 \mathrm{ppm}$

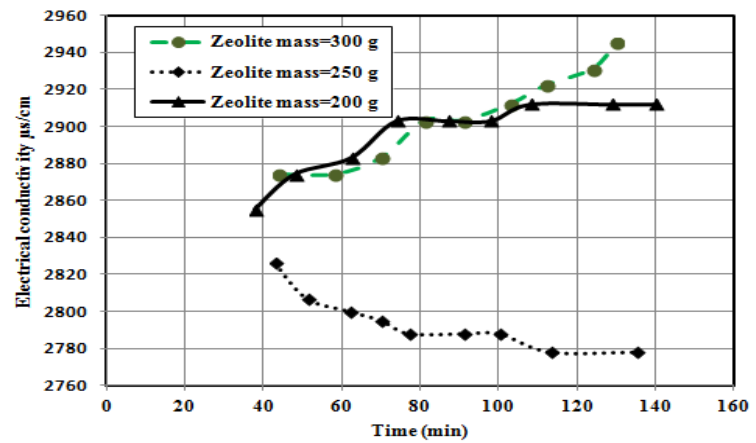

Figure 3. Variation of the produced water solution electrical conductivity with time for different amount zeolite mass in the zeolite bed when solution TDS $=1660 \mathrm{ppm}$ 


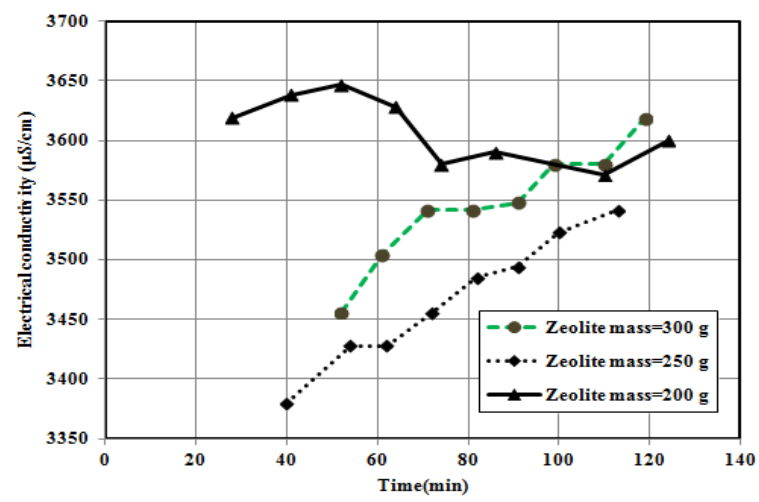

Figure 4. Variation of the produced water solution electrical conductivity with time for different amount zeolite mass in the zeolite bed when solution TDS $=2020 \mathrm{ppm}$

That is because this is the best weight for our bed size to make good contact between zeolite and water solution and enhances the diffusion process for Sodium ions in zeolite particles.

The effect of zeolite particle size ranging from $0.5-6 \mathrm{~mm}$ on produced water electrical conductivity is investigated experimentally. In these experiments, the experimental conditions were selected to be; the solution concentration of $2020 \mathrm{mg} / \mathrm{L}$, electrical conductivity of $4058 \mu \mathrm{S} / \mathrm{cm}, \mathrm{pH}$ of 7.5 and zeolite mass of $250 \mathrm{~g}$. Fig. 5 illustrates the variation of the IX produced water electrical conductivity with time for different zeolite particle size and indicates that as particle size decreases, the produced water electrical conductivity decreases. This is due to that as zeolite particle size decreases, the surface area/volume ratio of the natural zeolite increases. And for small particle the diffusion path is short and it will be easy for zeolite to adsorb solute ions.

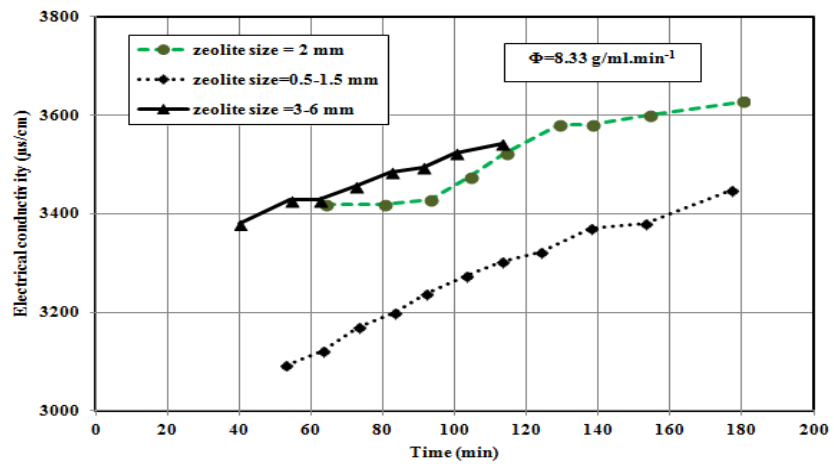

Figure 5. Variation of the produced water electrical conductivity with time for different zeolite particle sizes

\section{B. Theoretical results}

In this section the experimental results will compared with the theoretical results to verify the theoretical model. Moreover, some more working parameters with wide range will be studied. Figs. 6 to 8 show the relation between IX produced water concentration and time for different inlet TDS values, when ratio of zeolite mass to water flow rate $(\Phi)$ is $8.33 \mathrm{~g} / \mathrm{ml} \cdot \mathrm{min}^{-1}$ (equivalent to $250 \mathrm{gm}$ zeolite mass and 30 $\mathrm{ml} / \mathrm{min}$ water flow), for experimental and theoretical results. It can be seen from these figures that the produced water concentration sharply decreases by $7.21 \%$ to $16.3 \%$ at first and then increases with time for experimental results. This is because the natural zeolite uptake the sodium ions and this lead to TDS reduction. Also, from Fig. 8, we can see that there is nearlly concentration reduction of $16.3 \%$ for experimental and theoretical results at the same time (40 $\min )$.

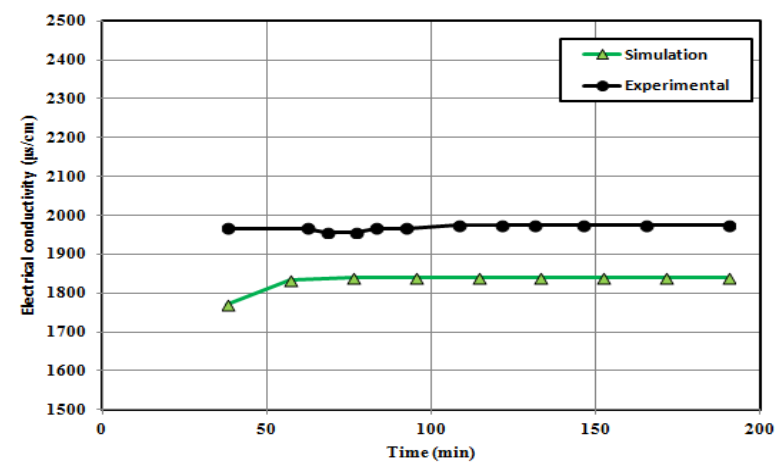

Figure 6. Produced water concentration versus time at $1060 \mathrm{mg} / \mathrm{L}$ inlet water $\mathrm{NaCl}$ concentration

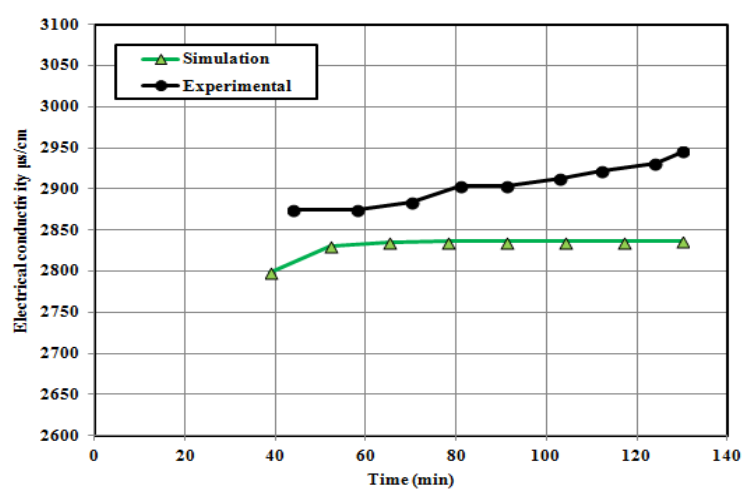

Figure 7. Produced Water concentration versus time at $1660 \mathrm{mg} / \mathrm{L}$ inlet water $\mathrm{NaCl}$ concentration

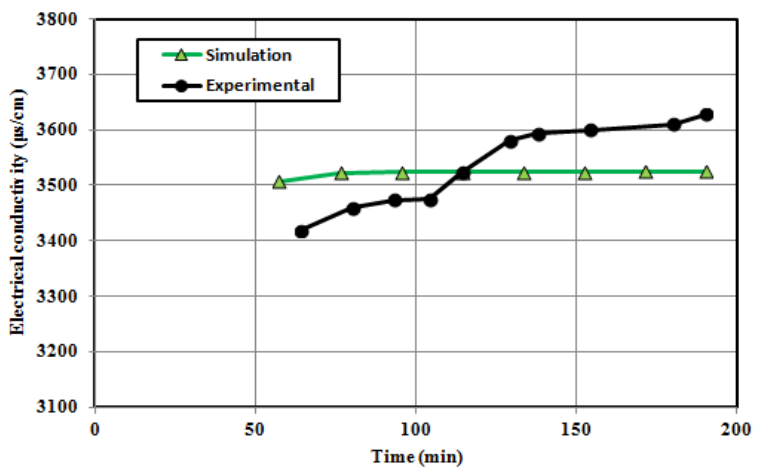

Figure 8. Water $\mathrm{NaCl}$ concentration versus time at $2020 \mathrm{mg} / \mathrm{L}$ inlet water concentration

Fig. 9 illustrates the relation between IX produced water electrical conductivity and time for different water flow rates. The inlet water $\mathrm{NaCl}$ concentration is $2020 \mathrm{mg} / \mathrm{L}$ and zeolite weight is $250 \mathrm{~g}$. It could be noted that as water flow rate decreases, IX produced water electrical conductivity decreases. This is because as water flow rate decreases, the contact time between water and zeolite will be increased and hence the adsorption equilibrium can be reached. The best reduction in the electrical conductivity is by $45.1 \%$ which is occurred at $10 \mathrm{ml} / \mathrm{min}$ water flow rate with about $120 \mathrm{~min}$ 
experiment time. The electrical conductivity reduction for 30 $\mathrm{ml} / \mathrm{min}$ is about $16.9 \%$ which is very close that obtained experimentally, which was about $16.7 \%$ as in Fig. 4.

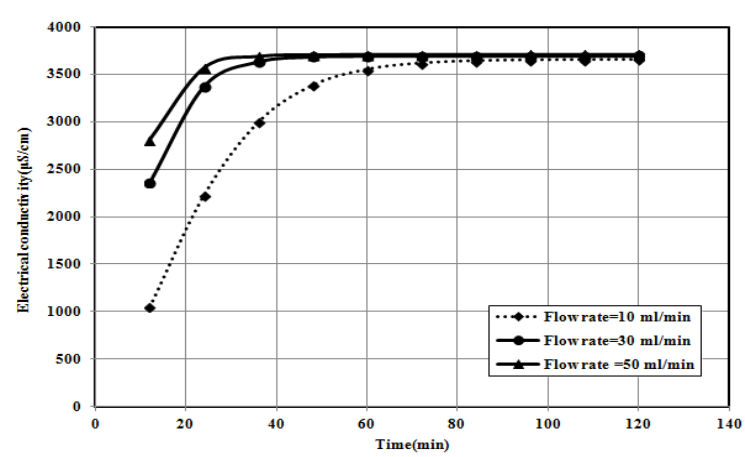

Figure 9. Effect of water flow rate on the produced water electrical conductivity

Fig. 10 shows the effect of zeolite bed diameter with fixed bed height $(10 \mathrm{~cm})$ on IX process performance theoretically. It shows that the increase of zeolite bed diameter enhanced the performance of IX zeolite bed. The electrical conductivity of the produced water is decreased from $3500.5 \mu \mathrm{S} / \mathrm{cm}$ to $1001.7 \mu \mathrm{S} / \mathrm{cm}$, when the bed diameter is increased from $5 \mathrm{~cm}$ to $15 \mathrm{~cm}$. This is because increasing the bed diameter will increase the contact time between zeolite and water solution. It should be noted that bed aspect ratio (1ength/diameter) should be between 2 to 7 in [22], this to avoid the difficulty of distributing the feed over the area of the bed. Also, it can be noted that the most improvement in IX process is happened by changing the bed diameter from $5 \mathrm{~cm}$ to $8 \mathrm{~cm}$, which can be taken as the best diameter for present bed.

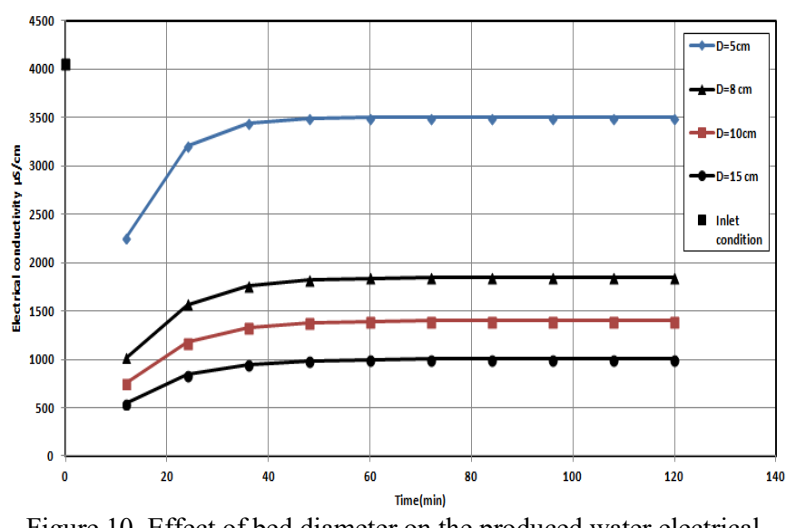

Figure 10. Effect of bed diameter on the produced water electrical conductivity

C. Performance enhancement of hybrid reverse osmosis desalination system

In this section, the effect of adding a new zeolite bed on the performance of reverse osmosis (RO) desalination system will be studied experimentally. This is done by studying the membrane water recovery and salt rejection percentage.

Fig. 11 shows the relation between RO membrane recovery, $\mathrm{Re} \%$, and feed water concentration without IX bed and with IX bed for different weights of zeolite bed (200, 250, and $300 \mathrm{~g})$. It could be seen that as feed water concentration increases, membrane recovery (Re\%) decreases. Moreover, adding IX bed to RO system improves the performance of RO system. This is because IX bed decreases water electrical conductivity, which decreases the osmotic pressure of feed water and hence increases membrane permeate, which increase membrane recovery. The Membrane recovery is increased by $9 \%$ to $27.1 \%$, when zeolite IX bed with $250 \mathrm{~g}$ weight was added for different concentrations. Finally, the higher membrane recovery has been occurred for $250 \mathrm{~g}$ zeolite mass.

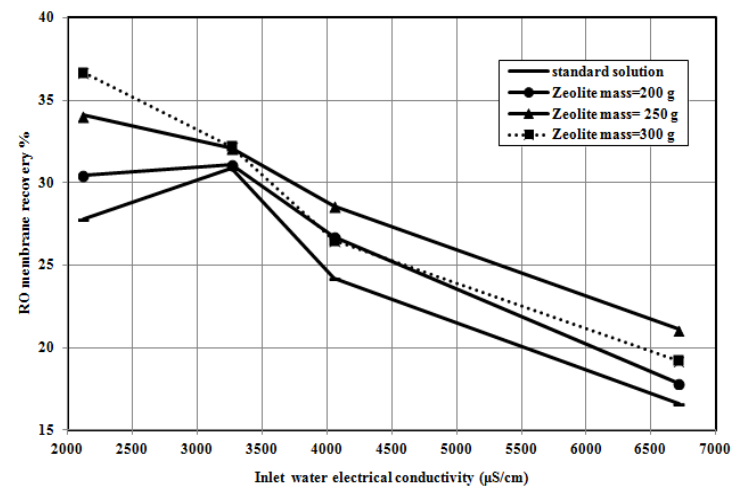

Figure 11. Effect of adding IX bed on RO membrane recovery for different amount zeolite mass in the zeolite bed

Fig. 12 shows the effect of the inlet water concentration on permeate increasing ratio due to using IX bed for different masses of natural zeolite in the IX bed. Permeate is enhanced by ratio from $8.5 \%$ to $29 \%$ for water treated by IX bed with $250 \mathrm{~g}$ zeolite mass. Therefore, in the present studied range, the optimum ratio between natural zeolite mass per $\mathrm{ml} / \mathrm{min}$ of water flow rate is 8.33 .

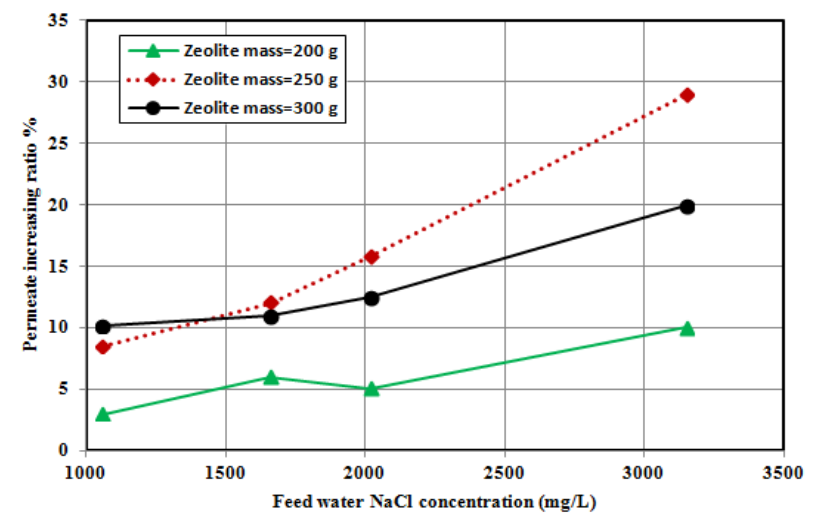

Figure 12. Effect of feed water concentration on permeate increasing ratio for different natural zeolite IX weights.

Fig. 13 compares between salt rejection percentage for $\mathrm{RO}$ system without IX bed and with natural zeolite IX bed for different water solution concentrations. It is clear that the salt rejection decreases when the inlet water concentration increases. This is due to the increasing of osmotic pressure of the feed water. Also, it could be seen that adding natural zeolite IX bed has nearly no effect on the system salt rejection. Therefore, using IX bed before RO process will increase the membrane water permeate without affecting its salt rejection. Finally, Fig. 14 compares between membrane flux for RO system without IX bed and with natural zeolite 
IX bed for different feed water electrical conductivity. It could be seen from this figure that the membrane flux is enhanced by using IX bed. At inlet water electrical conductivity of $6712 \mu \mathrm{S} / \mathrm{cm}$, hybrid RO system membrane flux is higher than that for conventional RO system by $30 \%$.

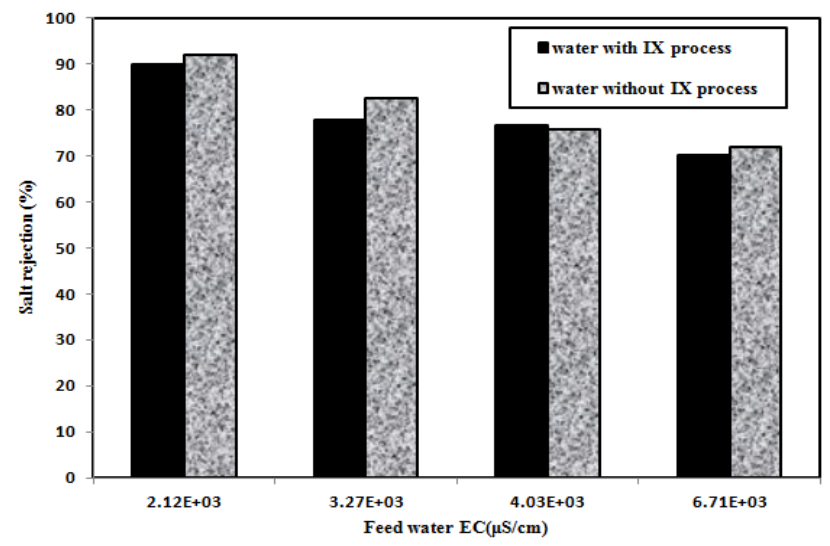

Figure 13. Comparison between salt rejection percentage for RO system without IX bed and with natural zeolite IX bed at different water solution concentration

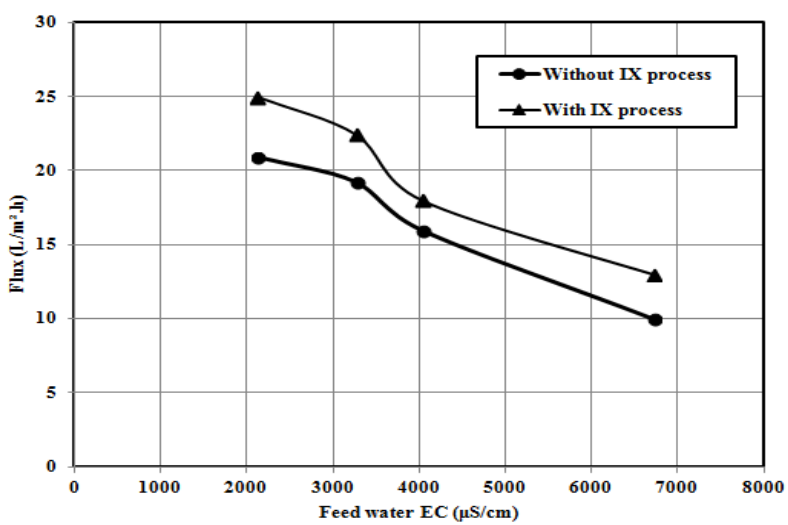

Figure 14. Membrane flux for proposed system and conventional RO system at different inlet feed water electrical conductivity.

\section{CONCLUSION}

A novel hybrid IX (ion exchange) reverse osmosis (RO) system is designed and investigated experimentally and theoretically. The performance of IX process in continuous water flow is examined. The effect of adding natural zeolite bed as IX bed before RO system is studied. From the experimental and theoretical results, it could be concluded the following proof of concepts:

1. IX process using natural zeolite works effectively in a continuous water flow system.

2. The smaller zeolite size particles, the higher IX performance is obtained.

3. In the present studied range, the optimum ratio between natural zeolite mass and water flow rate is 8.33 at which highest IX process performance is obtained.

4. IX process is simulated theoretically and has a fair agreement with experimental results

5. In the present studied range the best water flow rate and bed diameter for zeolite IX process is predicted.
6. The proposed hybrid system has higher performance and lower osmotic pressure than that for the conventional RO system.

7. The proposed system water recovery, permeate water and membrane flux is higher than that for conventional RO system by $9 \%$ to $27.1 \%, 8.5 \%$ to $29 \%$ and $30 \%$ respectively for $250 \mathrm{~g}$ zeolite bed at different inlet water concentrations.

\section{ACKNOWLEDGMENT}

Corresponding author is thankful to faculty of engineering- Kafrelsheikh University for lab measurements. Also, she wants to thank her supervisors for thhier valuable suggestions and help.

\section{REFERENCES}

[1] Jaewoo Lee, Rong Wang, Tae-Hyun Bae, "High-performance reverse osmosis membranes fabricated on highly porous microstructured supports," Desalination, vol. 436, pp. 48-55, 2018.

[2] M. Sarai Atab, A.J. Smallbone, A.P. Roskilly, "A hybrid reverse osmosis/adsorption desalination plant for irrigation and drinking water," Desalination, vol. 444, pp. 44-52, 2018.

[3] Parlar, I M. Hacıfazlıŏlu, N. Kabay, T.Ö. Pek, M. Yüksel, "Performance comparison of reverse osmosis (RO) with integrated nanofiltration (NF) and reverse osmosis process for desalination of MBR effluent," Journal of Water Process Engineering, vol. 29, 2018.

[4] N.M. Dube and R. Tzoneva, "Development of a Mathematical Model for Ion Exchange Process for Desalination of Water," The Fourth International Conference on Control and Automation (ICCA '03). WM05-6, pp. 579-583, 2003.

[5] Roberto T. Pabalan and F. Paul Bertetti, "Cation-Exchange Properties of Natural Zeolites," The Mineralogical Society of America, vol. 45(1), pp. 453-518, 2001.

[6] Rodney P. Townsend, "Ion exchange in zeolites: some recent developments in theory and practice," Pure \& Appl. Chem, vol. 58(10), pp. 1359-1366. 1986.

[7] Shaobin Wang and Yuelian Peng, "Natural zeolites as effective adsorbents in water and wastewater treatment," Chemical Engineering Journal, vol. 156, pp. 11-24, 2010.

[8] Frederick A. Mumpton, "La Rocamagica: Uses of natural zeolites in agriculture and industry," Proc. Natl. Acad. Sci. USA, vol. 96, pp. 3463-3470, 1999.

[9] Hongting Zhao, George F. Vance, Hongting Zhao, Michael A. Urynowicz, Girisha K. Ganjegunte, and Robert W. Gregory, "Integrated treatment process using a natural Wyoming clinoptilolite for remediating produced waters from coalbed natural gas operations," Applied clay sciencem, vol. 42, pp. 379-385, 2009.

[10] Edy Wibowo, Mamat Rokhmat, Sutisna, Riri Murniati, Khairurrijal and Mikrajuddin Abdullaha, "Thermally Activated Clay to Compete Zeolite for Seawater Desalination," Advanced Materials Research, vol. 1112, pp. 154-157, 2015.

[11] F. Shokrian1, K. Solaimani, GH.Nematzadeh and P.Biparva, "Removal of Nacl from aqueous solutions by using clinoptilolite," IJFAS, vol. 4(1), pp. 50-54, 2015.

[12] Edy Wibowo, Sutisna, MamatRokhmat, RiriMurniati, Khairurrijal and Mikrajuddin Abdullah, "Utilization of natural zeolite as sorbent material for seawater desalination," Procedia Engineering, vol. 170,pp. $8-13,2017$

[13] Oscar Santiago, Kerry Walsh, Ben Kele, Edward Gardner and James Chapman, "Novel pre-treatment of zeolite materials for the removal of sodium ions: potential materials for coal seam gas co-produced wastewater," Springer Plus, vol. (5) 571, pp. 1-16, 2016.

[14] George F. Vance, Hongting Zhao, Michael A. Urynowicz, Girisha K Ganjegunte, and Robert W. Gregory, "Potential utilization of natural zeolites for treating coalbed natural gas (CBNG) produced waters studies," Proceedings America Society of Mining and Reclamation, pp. 837-844, 2007.

[15] Sima Rezvantalab and Fatemeh Bahadori, "Application of Natural Zeolites on Wastewater Treatment," Asian Journal of Agricultural Research, vol. 9 (6), pp. 343-349, 2015.

[16] Arup K. SenGupta and Sudipta Sarkar Brackish, "Sea water desalination using a hybrid ion exchange-nanofiltration process," United States Patent, Patent No 7901577 B2, 2011. 
[17] Arup K. SenGupta and Sudipta Sarkar, "System and method for reversible cation-exchange desalination," United States Patent, Patent No 2010/0282675 A1 , 2010.

[18] A.E. Ghaly and M. Verma, "Desalination of saline sludges using ion exchange column with zeolite," American Journal of Environmental Sciences, vol. 4 (4), pp. 388-396, 2008.

[19] S.B. Patil and H.S. Chore, "Contaminant transport through porous media: An overview of experimental and numerical studies," Advances in Environmental Research, vol. 3(1), pp. 45-69, 2014.

[20] Birol Kaya and Amin Gharehbaghi, "Implicit Solutions of Advection Diffusion Equation by Various Numerical Methods," Australian Journal of Basic and Applied Sciences, vol. 8(1), pp. 381-391, 2014.
[21] S. F. Chung and C. Y. Wen, "Longitudinal Dispersion of Liquid Flowing through Fixed and Fluidized Beds," Aiche Journal, vol. 14(6), pp. 857-866, 1968.

[22] Helfferich and Friedrich G., "Ion Exchange Theory and Practice," J. Chem. Educ, Vol. 40(4), pp. 231, 1963. 